\title{
The impact of culture on mindreading
}

\section{Jane Suilin Lavelle ${ }^{1}$}

Received: 8 July 2019 / Accepted: 4 November 2019 / Published online: 14 November 2019

(c) The Author(s) 2019

\begin{abstract}
The role of culture in shaping folk psychology and mindreading has been neglected in the philosophical literature. This paper shows that there are significant cultural differences in how psychological states are understood and used by (1) drawing on Spaulding's recent distinction between the 'goals' and 'methods' of mindreading (2018) to argue that the relations between these methods vary across cultures; and (2) arguing that differences in folk psychology cannot be dismissed as irrelevant to the cognitive architecture that facilitates our understanding of psychological states. The paper concludes that any good account of social cognition must have the conceptual resources to explain how culture affects our understanding of psychological states, and that this explanandum should not be an after-thought but instead a guiding feature for those accounts.
\end{abstract}

Keywords Social cognition · Mindreading · Cross-cultural psychology · Folk psychology

\section{Introduction}

There is, so far, no human group that doesn't explain behaviour by imputing beliefs and desires to the behaviour. (And if an anthropologist claimed to have found such a group, I wouldn't believe him.) (Fodor 1989, p. 132).

So proclaimed the late Jerry Fodor, ardent defender of propositional attitudes and their explanatory value in understanding the causes of our own (and other people's) behaviours. Anthropologists and psychologists the world over have risen to this challenge, and the results are, unsurprisingly, complex. On the one hand, there is a catalogue of cultures where appeal to psychological states in everyday explanation is scarce (Henrich et al. 2010; Lillard 1998) or even taboo (Robbins and Rumsey 2008, p. 407). On the other, it is clear that humans can universally distinguish intentional

Jane Suilin Lavelle

j.s.lavelle@ed.ac.uk

1 School of Philosophy, Psychology and Language Sciences, University of Edinburgh, Edinburgh, UK 
from non-intentional behaviours, and there is growing evidence that we attribute some psychological states to others even when we are not aware of doing so (see Schneider 2017 for a review). If this is the case, then appeal to a folk-explanation of behaviour is not sufficient to support the claim that no psychological states are attributed to another in a given social interaction.

As both these observations seem sensible, the interesting philosophical work lies in figuring out how they fit together. This paper contributes to that aim by arguing that the current philosophical literature does not sufficiently account for the role cultural norms play in shaping our understanding of other people's behaviours. This has the unfortunate consequence that the explanandum (the phenomenon to be explained) these theories are striving towards does not accurately represent the nature of our social interactions. There are two strands to this argument. The first, developed in section four, builds on Shannon Spaulding's excellent work on the 'methods' and 'goals' of mindreading (Spaulding 2018b). Spaulding observes that our explanatory goals when assessing another person's behaviour are diverse: sometimes we just want a fast, not particularly accurate explanation of the behaviour; sometimes we need a more detailed account; and sometimes our aim is not explanatory at all, but rather to persuade the other person to act in a particular way, i.e. 'mindshaping' (Zawidzki 2008, 2013; McGeer 2007). Consequently, the methods we use when understanding other people's behaviour vary in accordance with our goals. This paper maintains that this observation is good as far as it goes, but that it does not sufficiently recognise that the methods associated with the goals will vary depending on background commitments the explainer has: commitments that are shaped by cultural considerations. What in North America may be a strategy for explaining another's behaviour when the outcome does not much matter to you, in East-Asian cultures may be a strategy used for explaining the behaviour of close kin. This argument segues to the second (section five), namely, that while culture shapes our explanations for behaviour at a folk-level, the influence goes further than this, to affect the cognitive mechanisms which bring about those explanations. Although it further complicates the dialectic about whether attributing mental states to others is essential for social cognition, recognising this feature is critical for philosophical accounts of how folk- and cognitive explanations of behaviour fit together.

The following section briefly sets out key terms and in so doing further delimits the scope of the paper. Section three presents two case studies that will be used to support the arguments made in sections four and five. Section six offers conclusions and further directions for research.

\section{Conceptual geography}

The terms 'folk psychology' and 'mindreading' are often used interchangeably in the philosophical (and psychological) literature on social cognition. It's therefore helpful to stipulate how these terms will be used in the following sections.

'Mindreading' will refer to the process of attributing psychological states to other people, and will be used in the broadest sense of attributing any kind of psycho- 
logical state to others. This runs against much of the philosophical literature which starts out with the assumption that mindreading consists in attributing propositional attitudes to others, before disagreeing about how such a process might be occur. ${ }^{1}$ Recent approaches have laid out two types of challenge to this view. The first is that mindreading may not (solely) consist in attributing propositional attitudes to others, and in fact that much mindreading occurs by attributing other kinds of psychological states to others [e.g. character traits (Andrews 2008, 2012; Westra 2017, 2018), or simpler analogues to propositional attitudes (Apperly and Butterfill 2009; Butterfill and Apperly 2013; Low et al. 2016)]. The second challenge is that philosophers may have over-estimated the prevalence of mindreading, and that in fact many social interactions happen fluidly without attributing psychological states to others at all (Ratcliffe 2006, 2007; Andrews 2012; Zawidzki 2013). Sections 4.3 and 5.3 develop the idea that this may be due to most philosophers in the area being grounded in a Western cultural mindset that favours giving explanations of other people's behaviours that cite their psychological states.

'Folk psychology' refers to our everyday understanding of our own, and other people's minds. It is typically contrasted with an expert, or scientific understanding of psychological constructs (although scientists may well be influenced by their folk psychology, as will be discussed in Sect. 5.3). For instance, when Mo says "I like Bo because she is really smart", a professional psychologist may look at Mo's behaviour and decide that he actually likes Bo because her eyes are slightly larger than average, and that her cleverness has little to do with his judgement. Mo's self-diagnosis of 'liking Bo for her smarts' relies on his concept of 'liking', and 'liking' is a psychological state. 'Folk psychological explanations' are explanations of behaviour that involve everyday constructs like 'liking' or 'wanting' or 'hoping' etc. As will become apparent in later sections, there are significant differences across folk-psychologies. North Americans tend to use folk psychology a lot to explain behaviours, appealing much more to the psychological states that caused a behaviour than folk in other cultures. But, as mentioned in the introduction, this is far from standard across the world. In some Pacific Island cultures it is taboo to talk about psychological states, so they feature very little in explanations of behaviours (Barrett et al. 2013a; Robbins and Rumsey 2008). Other cultures place more explanatory value on the context surrounding an action than the psychological state that caused it (see Sect. 3.3). And even within a relatively similar group of people folk psychologies will be different: one person may think that pride manifests itself in grandiose gestures, whereas another may think it causes quiet but fastidious actions. While folk-concepts share family resemblances across cultural groups, they are also highly varied.

If 'folk psychology' is the everyday lay understanding of psychological states, then 'mindreading' refers to those cognitive processes, whatever they may be, that underpin our ability to attribute psychological states to others. 'Mindreading' is the process that psychologists study when they think a person's responses evidence that they have attributed psychological states to someone else. The big question is how mindreading and folk-psychology relate. This paper largely side-steps that question, as

\footnotetext{
1 The standard 'theory-theory' (Carruthers 1996, 2006; Gopnik and Wellman 2012; Stich and Nichols 1992; Wellman 2014) versus 'simulation' (Goldman 1992; Goldman et al. 2006; Gordon 1992) debate exemplifies this approach.
} 
there simply is not the space to evaluate the different positions regarding the conceptual resources of mindreading and folk-psychology. Where the paper will take a stance, however, is in saying that cultural considerations as manifested in folk-explanations do affect the cognitive mechanisms facilitating mindreading, and that their influence has been unfairly overlooked in the philosophical literature. This is likely due to a tacit conflation of mindreading and folk-psychology, and an assumption that if one can show that mindreading occurs, then differences at the folk-level of explanation can be largely ignored. Consequently, future analyses of mindreading processes need to take cultural factors into consideration, even if those analyses purport to be solely within the realm of mindreading.

\section{Independent and inter-dependent concepts of self}

This section draws on research in cultural psychology regarding different perspectives on the self. The following sections consider how these differences impact philosophical analyses of folk psychology and mindreading.

\section{1 'Collectivism' and 'Individualism'}

A broad distinction is made in cross-cultural psychology and related disciplines between "Collectivist" and "Individualistic" cultures (Nisbett 2004; Oyserman et al. 2002; Schwartz 1990; Triandis 1995). Individualistic cultures prioritise the autonomy of the individual, whereas Collectivist cultures prioritise group cohesion and harmony. Although well-used, these labels are now acknowledged to be too broad to map interesting differences or generate viable hypotheses (Miller 2001, 2002). To illustrate this, take the example of Iranian and Chinese communities, which both value suppressing inter-personal differences in order to maintain a harmonious family life, a trait which puts them both under the "Collectivist" label. In Chinese populations this is typically achieved through filial piety, with strong deference from children to their elders, which in turn is maintained through an authoritative parenting style where disobeying one's parents is firmly disciplined (Chao 1994). Iranian families also prize harmony, but mothers often achieve this through avoiding conflict with their children when they misbehave by remaining silent and ignoring the misdemeanour. This reinforces the social norm that expressing your disagreement with someone is frowned upon, as it disrupts familial harmony, while also demonstrating the laudable quality of self-control by hiding the fact that the child has annoyed you (Shahaeian et al. 2014, p.1119). While the "Collectivism" label captures both Iranian and Chinese priorities for reducing inter-personal conflict, it is unable to generate specific or testable hypotheses for how this might be manifested in a family setting. It is only when one takes the time to grasp the values underlying the (behaviourally) opposing parenting styles that one is able to see the collectivist commonality between the groups.

Although the "Collectivist" and "Individualistic" labels are broad, they do track general trends that vary across cultures. One trend of interest for the mindreading literature is how one's cultural values affect one's perception of self-hood and agency. 
Collectivist cultures emphasise inter-dependence, seeing the individual as inherently part of a network, from the (relatively) small family group extending out to your local society and further to broader society and your place within it (Markus and Kitayama 1991). One way in which this value manifests itself is through individuals' strong identification with their role within the family and broader society, e.g. as a daughter or a father, a lawyer or a brick-layer (Miller 1984; Nisbett et al. 2001, 2004). The shape of these roles are determined outwith the individual, by the social norms of the culture. For example, Chinese cultural norms expect children to be unquestioningly obedient to their parents, and children identify with this norm, striving to fulfil their parents' wishes and goals (this example is discussed further in 3.2). What one should want and aim towards is set by the external norms that society has associated with your particular role. By contrast, individualistic societies prioritise what the individual wants, rather than what the individual should want given their particular place in society (Markus and Kitayama 1991, 230). Here emphasis is on the independence of the individual, rather than on an inter-dependent relation with others.

It is important not to conflate a cultural emphasis on inter-dependence with an eradication of the self and agency. Such a conflation seems apparent in the following passages:

"In collectivist cultures [...] people think of themselves as parts of their collective and in most situations subordinate their personal goals to those of their collectives" (Triandis 1995, xiii).

"The understanding of one's autonomy as secondary to, and constrained by, the primary task of interdependence distinguishes interdependent selves from independent selves, for whom autonomy and its expression is often afforded primary significance.” (Markus and Kitayama 1991, 227)

However, as Markus and Kitayama clarify later in their paper,

"An interdependent view of self does not result in a merging of self and other, nor does it imply that one must always be in the company of others to function effectively, or that people do not have a sense of themselves as agents who are the origins of their own actions. On the contrary, it takes a high degree of self-control and agency to effectively adjust oneself to various interpersonal contingencies." (Ibid. p. 228)

A desire to meet the goals set for you by others is still your own desire. In striving to meet societal norms, and to fit harmoniously with the collective, one is still exercising one's own agency. The contrast is not between degrees of agency, as implied by Triandis' claim that participants in Collectivist cultures 'sub-ordinate' their personal goals, but rather between the content of the agents' desires. In a Collectivist society, one's personal goal is to meet societal roles and expectations; in an Individualistic society it is less important that one's personal goals align with those that others have for you. One prediction of this hypothesis about different desires is that participants in Collectivist cultures should feel more positive affect when meeting the goals that others have set for them than participants in Individualistic cultures. One study supporting this prediction showed that Asian-American third- and fourth-graders were more persistent 
and motivated to succeed on puzzles picked out for them by a parent in contrast to puzzles they had chosen for themselves (Iyengar and Lepper 1999). By contrast, Anglo-American children were strongly demotivated to complete tasks chosen by their parents, preferring instead the self-chosen puzzles. ${ }^{2}$ Similar attitudes prevail in other East Asian cultures, including Taiwan (Miller et al. 2002), South Korea (Iyengar and Lepper 1999) and Japan (Dennis et al. 2007).

The rest of this section develops the analysis of the collectivist concept of self through case studies, and demonstrates how different concepts of self-hood affect explanations and understanding of behaviour.

\subsection{Autonomy and parental control}

East Asian parenting styles are usually perceived (in the West) as strict and authoritarian. But, as Chao (1994) highly influential paper argues, most studies of parenting styles (designed in North American universities) fail to capture the East Asian association of strict parenting with love and concern for the child: Guan is a Chinese term meaning 'to govern' and is used to describe parent-child relationships, but it also means 'to care for' or 'love' and has very positive connotations (Ibid. p. 1112). Chinese culture maintains that parents demonstrate their love for their children by governing them well: making decisions for them, and devoting many hours to ensuring their children's academic achievements - a key societal marker of a successful individual. ${ }^{3}$ Children are lavished with praise within the home when they obey their parents and meet their expectations (Chua 2011), and so learn to value these behaviours and to find them rewarding. Furthermore, they trust their parents to make the best choices for them (Barrett et al. 2013b, p. 8), and are more motivated than North American children to succeed in the tasks parents set for them (see above).

The 'governance' conception of the parent-child relationship affects both children's self-perception and adults' attitudes to children's psychological states. Children selfidentify with the roles set out for them by their parents and elders, taking pride in fulfilling these roles and expecting those in authority to choose what is best for them. In their turn, parents do not solicit children's views or opinions in decision-making, as they assume that the child wants to do what their parents expect of them. This is in keeping with the inter-dependence of collectivism, where the child's concept of self is inherently tied to what their parents and those in authority expect of them.

\footnotetext{
2 A further prediction is that participants in Individualistic cultures should value choice and variety more highly than those in Collectivist cultures, as 'choosing for yourself' from a range of options is a way of expressing one's own personal agency. This is one of the most studied differences across Collectivist and Individualistic cultures, with a significant body of research claiming to support this prediction (Heine and Lehman 1997; Henrich et al. 2010; Iyengar and Lepper 1999; Kim and Sherman 2007; Miller 2001); a detailed analysis of this work, however, is beyond the scope of this paper.

3 Academically successful children are also more likely to attain high-earning jobs, in turn allowing them to financially support their parents and their own children. This further reflects the value of dependence between parent and child (Fu and Markus 2014).
} 


\subsection{Social expectations and explanations}

Looking beyond the parent-child relationship, societies where individuals self-identify through their connections with others often cite social roles in their explanations of behaviour, and certainly do so more than societies where the self is perceived in a more independent way. Two examples illustrate this.

The first example is Morris and Peng's (1994) analysis of Chinese language and American newspapers' accounts of two mass murders. The first was a Chinese graduate student who had lost an award competition and subsequently failed to get an academic posting. He shot his advisor, the person handling the award process, several bystanders and then himself. The second was an Irish-American postal worker who lost his job and was unable to find employment. He shot his supervisor, the person handling his appeal, several bystanders and then himself. A comparison of different newspaper reports revealed that the American press referenced the psychological state of the killer in each case, e.g. "a very bad temper", "a darkly disturbed man who drove himself to success and destruction", "mentally unstable". Chinese newspapers, by contrast, focussed on the relationships between the victims and the killer, e.g. "did not get along with his advisor", and the status pressures of being a top Chinese student "Lu was a victim of the 'Top Students' Education Policy". Morris and Peng argued that these differences in reporting revealed different priorities in East Asians' and North Americans' explanatory accounts of behaviour, with North American explanations highlighting inner psychological states as causes and East Asian accounts focussing on external, situational factors.

The second example comes from Joan Miller's early work contrasting HinduIndian explanations of behaviours with those of North Americans (Miller 1984). Miller and colleagues first asked participants to "narrate two prosocial behaviours and two deviant behaviours and to explain, immediately after narrating each behaviour, why the behaviour was undertaken" (Ibid. p. 965). They found that Hindu-Indians were significantly more likely to cite contextual factors in their explanations for behaviours than North Americans [e.g. "The man is unemployed. He is not in a position to give that money" (p. 968)], and that this disposition was stronger in adult participants than in younger participants (8 years, 11 years and 15 years). By contrast, while American participants were more likely to give explanations citing the protagonist's dispositions [e.g. "He was just a very self-absorbed person. He was only interested in himself" (p. 967)], "at older ages Americans gave greater weight to general dispositions in explanation than did Hindus" (p. 967). In a follow-up study, the researchers gave American college students a selection of the behaviours described by the Hindu participants in the first study, transcribed just as they described them (with culturally appropriate substitutions to mask obvious cultural cues, e.g. 'dollar' for 'rupee'). One anecdote describes an accident where a passenger falls from a motorcycle being driven by an attorney who was late for court. The attorney drives the passenger to hospital and then immediately leaves to attend court without waiting for a diagnosis of the injury. The passenger later dies. While both Hindu and American participants mentioned the psychological state of the driver in their explanations of his behaviour, American par- 
ticipants made multiple references to the driver's psychological states and dispositions, whereas Hindus cited additional contextual reasons in their explanations:

\section{"Explanation by Hindu adult subject}

It was the driver's duty to be in court for the client whom he's representing (context: social/spatial/temporal location); secondly, the driver might have gotten nervous or confused (agent: specific aspects); and thirdly, the passenger might not have looked as serious as he was (context: aspects of persons).

Explanation by American adult subject

The driver is obviously irresponsible (agent: general dispositions); the driver was in a state of shock (agent: specific aspects); the driver is aggressive in pursuing career success (agent: general dispositions).” (Miller 1984, p. 972)

Importantly, although contextual aspects of the situation were mentioned in the original anecdote (that the driver is an attorney late for court), American participants "overlooked such available information to concentrate on dispositional properties of the agent, factors that could only be inferred" (Ibid.). Hindu explanations focus on what could clearly be known about the situation, such as context and social role, but the American trend towards psychological state explanations led those participants to go beyond the immediately available information to speculate about possible psychological causes of the attorney's behaviour.

These studies show that different cultural outlooks-broadly Collectivist or Individualist - lead to a clustering of features relevant to mindreading and social cognition. When a group tends towards a Collectivist outlook, there is considerably less emphasis on another's psychological states in explanations of their behaviour, and non-psychological features relating to that person's role, as a parent, child or attorney, are given prominence in the explanations. Collectivist-oriented societies also foster an inter-dependent sense of self, where one's own self-construal is inextricably shaped by how you perceive the expectations others have of you. These expectations are also related to socialy construed role, e.g. what your mother expects of you as her child, or what an authority figure expects of you as a subordinate.

By contrast, Individualist-oriented cultures value the independence and autonomous choice of the individual, a feature that is reflected in a preference for explanations of behaviours that cite the actor's psychological states. What the agent thinks or feels about a situation is considered critical for understanding why they behaved as they did. This focus on the individual also predicts a difference in self-construal, for where Collectivist cultures see themselves in terms of how they relate to others, one would expect an Individualist self-construal to have far less emphasis on where one stands in relation to others. This prediction is discussed further in Sect. 5.2.

These differences in how mental states are used in behavioural explanations, and how one perceives oneself, have consequences for our understanding of mindreading. For a start, it suggests that thinking about other people's psychological states may or may not be a clear goal of your understanding of another's behaviour, dependent on your cultural situation. Secondly, it suggests that if your self-construal involves your relation to others and your understanding of their expectations of you, then selfconstrual could involve mindreading to a greater or lesser degree depending on how inter-dependent your concept of self is. The next two sections explore these claims. 


\section{Application to folk psychology and mindreading}

\subsection{Methods and goals of mindreading}

In her monograph How we understand others, Shannon Spaulding makes a useful distinction between the goals and methods of mindreading. Unlike traditional mindreading accounts that present the goal of mindreading solely as the attribution of beliefs and desires to other people in order to explain and predict their behaviour (Nichols and Stich 2003) Spaulding recognises that other outcomes are not only possible, but rife in daily social cognition; furthermore, the mindreading strategies we deploy (methods of mindreading) vary in relation to these mindreading goals.

Spaulding's treatment of stereotyping is of relevance to this paper. She uses 'stereotype' to cover "positive, negative or neutral beliefs about members of social groups" (Spaulding 2018b, p. 26). 'Stereotype explanations' of behaviour are a type of causal explanation on her account, as they "interpret a target's behaviour in terms of a more general category, which allows us to make predictions about future behaviour" (Ibid). When an agent uses a stereotype to understand a target's behaviour, the agent is basing her expectations of the target's behaviour on her own collection of beliefs about what that sort of person will do. But of most interest for the following sections is Spaulding's analysis of how and when stereotype explanations are used, i.e. the 'goal' of stereotyping explanations, claiming that we use them...

“... when we are motivated more by efficiency than accuracy, when the person we are mindreading is part of the out-group, and when we are more interested in categorizing the behavior as part of a more general pattern than intervening on an individual's future behavior." (Ibid. p. 55).

In line with other researchers (Apperly and Butterfill 2009; Apperly 2010), Spaulding sees 'accurate' mindreading as underpinned by cognitively effortful processes, with cognitively efficient processes generating less accurate, but in most cases 'good enough' mindreading. 4 'Accurate' mindreading is when we correctly attribute detailed psychological states to other people. It requires time, cognitive effort, and practice in reflective reasoning (Gilbert et al. 1988). Consequently, we reserve the goal of 'accurate' mindreading for situations where "something important depends on getting it right, when we will be held responsible for our interpretation of the interaction, or when the situation is unusual and unexpected (Fiske and Neuberg 1990; Tetlock 1992; Kelley 1973)" (Spaulding 2018b, 43). But if the situation calls for a quick assessment of another's psychological states, the reflective reasoning required for accurate mindreading is too slow, and so we use more cognitively efficient methods. How we go about efficient mindreading depends on how we perceive the target. When we judge the target to be similar to us, we are likely to achieve efficiency by attributing our own mental states to them (Ames and Mason 2012; Ames 2004). If we perceive the

\footnotetext{
4 The trade-off between cognitive efficiency and mindreading accuracy is what motivated Apperly and Butterfill's 'Two-systems' approach to mindreading (Apperly and Butterfill 2009; Butterfill and Apperly 2013). Critics have questioned whether such a trade-off is necessary, suggesting that accurate and efficient mindreading is possible (Carruthers 2016; Christensen and Michael 2016).
} 
target as being very different from us, then we are likely to use stereotyping to attribute ‘close enough' psychological states to them (Krueger 1998; Vorauer et al. 2000).

Returning to the quotation above, Spaulding's interpretation of when we use stereotype explanation is based on two empirically supported claims: that stereotype explanations are cognitively efficient and therefore a quick method of mindreading; and that we are more likely to use stereotyping to mindread out-group rather than in-group members. Both these claims are based on work using participants predominantly from North America and/or Northern Europe. But there is a third claim which demands further scrutiny. This is that stereotype explanations are used when "we are motivated more by efficiency than accuracy". In the next sections, I will argue that 'accuracy' in this context is taken to mean 'a detailed and accurate attribution of psychological states to others'. But this is a specific understanding of 'accurate mindreading' that may be relative to Individualist cultural values. A closer examination of the case-studies discussed in Sect. 3 reveals that not every culture understands 'accurate' social understanding in this way. This would suggest more flexibility in the way in which mindreading goals are related to the methods used to achieve them than is implied by Spaulding's discussion.

\subsection{Cultural differences in the goals and methods of mindreading}

East-Asian parenting practices rely on stereotype explanations. Children are expected to conform to a particular 'good child' stereotype, and it is the role of parents and teachers to help them to meet these expectations. Being told that your sister did $X$ because 'she's a good daughter' is a form of stereotype explanation. But if we contrast the goals that stereotype explanations aim towards in this example, they are quite different from those presented by Spaulding in the previous section.

First, stereotype explanations as used by parents to 'govern' children clearly contrast with the North American standard of using stereotype explanations in relation to out-group members: parent and child relations are amongst the closest kin, in-group relations one can have. Second, it is not the case in East Asian cultures that a stereotype explanation is used when the explainer is looking for an efficient rather than an accurate explanation. One may counter that the above explanation is not accurate, as an accurate explanation would reference the sister's psychological states. But such a response would reveal a cultural bias in associating 'accuracy' with 'psychological state attribution'. Stereotype explanations are accurate in the parent-child setting in China, because teaching a child to fulfil her role as 'a good daughter' shows the child her place within the broader family and social network; and understanding that place is the basis of self- and other understanding within Chinese culture. In a setting where the individual is 'trained' to fill a particular role, and in so doing comes to value filling that role, an explanation that appeals to that social role is perfectly accurate. Finally, one of the core goals of stereotype explanations in Chinese parenting is to intervene on the child's future behaviour. By telling a child that she is a 'good daughter', one is hoping to influence future behaviours by encouraging adherence to that stereotype. Similarly, being told that your sister is a good daughter is also intended to shape future behaviours: be more like your sister in conforming to the 'good daughter' stereotype. 
The goals for a stereotype method of mindreading in Chinese culture suggest that stereotype explanations are used when the explainer has a mindshaping rather than mindreading goal (see section one). Mindshaping is the practice of molding another person's behaviour so as to make it "more homogeneous and hence easier to predict and interpret" (Zawidzki 2013, p. 29). By telling a child that she is a 'good daughter', the parent aims to shape the child's behaviour to match that expected of a good daughter, and in so doing make the child's behaviour easier to predict. In Tad Zawidzki's mindshaping proposal (2013), he makes clear that the 'shapers' need not conceptualise the person they are trying to shape as having a mind. The criterion for successful mindshaping is that the other's behaviour conforms to the suite of dispositions you want them to have. Although success may depend on changing another's psychological states, the shaper need not have this as a goal. This is exemplified through the East Asian parenting case, where parents rarely solicit their child's opinions or explicitly discuss their mental states. Helping your child to meet the social stereotypes expected of them does involve changing their psychological states, e.g. to associate positive affect with pleasing their parents (Sect. 3), but the absence of discussion of a child's psychological states implies that this is not an explicit goal (Barrett et al. 2013b). Similarly, in those Pacific Island cultures where mention of another's psychological state is taboo, people nevertheless succeed in shaping the behaviours of those around them to conform with social norms (Barrett et al. 2013a, 2016; Robbins and Rumsey 2008). Such changes require influencing another's thoughts, without necessarily knowing that this is what you are doing.

This contrasts with Spaulding's example of mindshaping: "When you tell an underachieving student that you know he wants to do well in the class, part of what you are doing is encouraging him to adopt that desire and act accordingly" (Spaulding 2018b, p. 44). The lecturer explicitly attributes a particular psychological state to the student (the desire to do well in the class) and makes him aware of this attribution, in order to shape his behaviour. This is an example of mindshaping that explicitly aims to change the target's psychological states. In an Individualist-oriented culture that emphasises the importance of psychological states to behaviour, such explicit cases of mindshaping may be more common, in contrast to cultures where there is less emphasis on internal psychological states. Mindshaping may or may not involve explicit reasoning about the target's mind; in the North American context it is more likely to involve explicit mindreading, but in the East Asian context this is less prevalent.

One critique of this analysis is that we do not need to look all the way to China to uncover the contrasts just discussed: North American parents can give stereotype explanations of their children. A mother may explain her child's caring attitude towards her parents by saying 'she's a good daughter'. This observation strengthens the core argument of this section: that appeal to stereotype explanation is not exclusively reserved for quick (rather than accurate) mindreading of out-groupers. The mother may have 'accuracy' as an explicit aim; perhaps she is in awe of the care her daughter lavishes on her and is deliberating about the causes of her daughter's behaviour. The mother can't pin the behaviour to any specific set of psychological states, but instead finds the explanation 'because she's a good daughter' most accurately captures the suite of motivations that cause the behaviour. The mother is not aiming for a shallow, 
quick analysis of her daughter, yet the explanation she finds most satisfying does not explicitly reference propositional attitudes or other psychological states.

Work in social psychology suggests that certain methods of mindreading are reliably associated with particular mindreading goals (Sect. 4.1). But these characterisations are not exhaustive. In East-Asian parent-child relationships, accurate explanations of close kin can be achieved by reference to stereotypes, and this method of explanation is more prominent in this context than, say, in the US. But even with North American cultures stereotyping explanations can be used to with the goal of accurately explaining the behaviour of a loved one. While Spaulding observes that the methods and goals of mindreading interact in 'messy and complicated ways' (Spaulding 2018b, 18), the relations are even more messy and complex than her initial analysis implies. Two people with the same goal of accurate mindreading may engage in different methods to achieve it: above the Mother uses a stereotype explanation, but one could also imagine a friend of the daughter offering a more explicitly mindreading explanation, e.g. 'she believes her Mother deserves good care'. In these cases it is not clear that we can predict which method of mindreading a person will use to attain their goal of accurate understanding of the other: much will depend on the explainer's own understanding of how particular beliefs affect behaviour (Curry 2018; Heyes and Frith 2014).

\subsection{Cultural differences in whether mindreading is a goal at all}

The previous section discussed cases where the goals and methods for mindreading can be different depending on background cultural commitments. This section discusses cases where there are differences in whether mindreading is a goal of the interaction at all. Specifically, it examines cases where North American cultural biases cause agents to have a mindreading goal, but where agents from cultures with more collectivist leanings do not have mindreading as the goal of the social interaction or explanation. While the aim of Spaulding's monograph is to analyse mindreading, ${ }^{5}$ there is value in seeing how her analysis could apply to cases where mindreading is arguably less central.

Section 3.3 described differences in Hindu-Indian and North American descriptions of behaviour. Notably, North Americans seemed more concerned with the psychological profile of the motorcyclist, focusing on his dispositions as explanatory for the incident even when contextual information was available, whereas Hindu-Indians cited multiple contextual reasons for the behaviour, and only one or two dispositional features of the driver. Similarly, Morris and Peng's analysis of the newspaper reports reveal that North American papers speculate about the psychological causes of the murderer's behaviour, whereas Chinese-language papers discuss the situational factors leading to the murders. These are cases where the broad explanandum is the same:

\footnotetext{
5 Spaulding (chapter one) does engage with accounts of social cognition which give mindreading a much less central role in social cognition than is typically recognised by more traditional accounts, e.g. 'Interactive' social cognition (Gallagher 2008; De Jaegher et al. 2010) and 'Enactive' social cognition (Hutto 2008, 2017; Kiverstein 2011). However, these accounts aim to describe the mechanisms of social interaction at a more fine-grained level than discussed in this section, e.g. how to recognise goal-oriented or intentional behaviour without attributing psychological attributes to the other; as such, they can be set aside for the purposes of this piece.
} 
'Why did the attorney act as he did?' or 'Why did the agent engage in mass murder?' but the explanans (that which does the explaining, i.e. features of the explanation) preferred by Hindu-Indians and Chinese, and North Americans, were quite different. These choices of explanans in turn reveal different conceptions of the explanandum: while the over-arching explanandum remains the same for the two groups, they each parse it differently: 'what were the contextual features such that murder occurred', versus 'what were the thoughts that drove him to murder?'. The North American group assume that a good explanation will point to psychological features and so have a mindreading goal, whereas Hindu-Indians and Chinese do not have a mindreading goal in this situation. Hence, not only can a situation lead to different mindreading methods across populations, as discussed in the previous section; the same situation can give rise to different explanatory goals across populations too.

\section{Mindreading and the folk}

This section addresses the concern that the case-studies just discussed do no more than illustrate different folk psychologies. Cultural considerations may well affect the prevalence of mental state attribution at a lay-level of understanding, but dig below folk psychology and a different story emerges: mindreading remains as central and indispensable as ever before. In what follows, I argue that glossing the aforementioned case-studies as mere differences in folk psychologies would be a serious mischaracterisation of the phenomenon that is social cognition for two reasons: first, it runs the risk of eroding genuine and explanation-worthy differences between groups; and second, scientists are folk too, whose own cultural biases may affect their hypotheses about the cognitive architecture of social cognition.

\subsection{Mindreading: still front and central?}

Here is an argument for the centrality of mindreading in social interactions, which I suspect was the type of argument Fodor had in mind when he made his sweeping statement about propositional attitudes (Sect. 1).

1. Recognising another person's behaviour as intentional requires attributing a psychological state to them.

2. Both Hindu-Indians and North Americans perceived the attorney's actions as intentional (This premise still stands even if they attributed different intentions to the attorney)

3. (Conclusion) Therefore despite differences in explanations for the attorney's behaviour, both populations' evaluation of the situation required attributing psychological states to the attorney (i.e. mindreading).

There is a rich literature discussing whether perceiving another's behaviour as intentional requires attributing something psychological to them, so premise one is clearly controversial (De Jaegher et al. 2010; Hutto 2008, 2017; Kiverstein 2011). However, as the current aim is to assess whether we can dismiss differences in folk-explanation as irrelevant to mindreading, let's allow that premise to stand uncontested. If it turns 
out that premise one is false, then it will form an independent challenge to the centrality of mindreading to social cognition.

The above argument highlights the necessity of mindreading as a foundation to explaining intentional behaviour. And perhaps necessity is what Fodor meant when he claimed that every population explains behaviour by "imputing beliefs and desires to the behaviour" (1989, p. 132). But a more relevant explanandum to the task in hand is not what is necessary to an explanation of another's behaviour but rather what is sufficient. Recognising a behaviour as caused by psychological states is necessary for grounding an explanation of that behaviour (as it marks that behaviour as intentional), but it is not always sufficient, as evidenced in section three. Reports in the Chinese language newspapers focussed on non-psychological features of events, implying that mention of these features was deemed necessary in order to create a satisfying explanation of the behaviour for their readers. Similarly, Hindu-Indian explanations of the attorney's actions all featured non-psychological aspects, again implying that these were considered necessary to provide a satisfying explanations. Fodor's comment is reminiscent of a particular myopic view of social cognition which focusses solely on mindreading, ${ }^{6}$ a view that resonates most closely with an Individualist-oriented perspective. $^{7}$

This observation affects how we study the cognitive mechanisms that facilitate our understanding of behaviours. As argued in Sect. 4.3, two populations can differ in how they frame the explanandum for a behaviour, with one population asking 'What psychological states caused the behaviour' and another asking 'What contextual features caused the behaviour'. In the first population, we may expect the cognitive mechanisms that track psychological states to be more active in generating explanations; in the second we might expect cognitive mechanisms that track relations between the individual and the environment to be more salient. While both sets of cognitive mechanisms are likely to be active in both populations, we might expect them to have different weighting dependent on the relevant folk-norms for explanations. This would then be a case where a difference in folk-level of explanation manifests itself at the level of cognitive architecture.

Mindreading is necessary to ground explanations of behaviour, and this is the case across cultures. But researchers need to be open to the possibility that differences in folk-explanations may well manifest themselves at a non-folk level, in the cognitive architecture that facilitates the generation of explanations. Folk-explanations indicate that while everyone uses mindreading, it may not be used to the same extent, or granted the same weighting across populations.

\subsection{Cross-cultural neuroscience}

There is a research tradition going back at least to Vygotsky's work (1980) demonstrating that culture can affect the neural correlates of cognitive abilities (e.g. perception

\footnotetext{
${ }^{6}$ For criticisms of this position see (Andrews 2012; Lavelle 2018; Spaulding 2018c)

7 'Resonates most closely with', because the view that social cognition consists solely, or even primarily, in mindreading is a caricature that does not accurately describe even the most Individualist cultural outlook (Hutto 2008; Morton 2003; Ratcliffe 2007).
} 
of foreground and background (Gutchess et al. 2006) and colour perception (Davidoff 2001)). More recently, researchers have examined whether the interdependent selfconstrual associated with Collectivist cultures, and the independent self-construal associated with Individualist cultures, has an effect on the neural correlates of certain cognitive processes, e.g. perception, arithmetic cognition, and mindreading (Han and Humphreys 2016; Kitayama and Park 2010; Ma et al. 2014). This section discusses work consistent with the claim of the previous section, namely, that cultural differences can affect the neural structures involved in social cognition.

Two brain regions are of particular relevance to this research: the medial prefrontal cortex (mPFC) and the temporal parietal junction (TPJ). The TPJ has been argued to be critical for 'mentalising', that is, thinking about psychological states and attributing them to other people (Koster-Hale and Saxe 2013; Saxe and Kanwisher 2003; Saxe 2013). The medial prefrontal cortex (mPFC) has been shown to be active when people are asked to make judgments about themselves, suggesting that it is implicated in representations of the self (Craik et al. 1999; Heatherton 2011; Kelley et al. 2002; Lieberman et al. 2004; Zhang et al. 2006). The imaging data taken to support these interpretations of TPJ and mPFC functioning comes overwhelmingly from North American and Northern European participants, and the interpretations are, predominantly, made by scientists in those countries.

If the mPFC region supports self-judgments, then we should expect to see a difference in its activity across populations with an inter-dependent rather than independent concept of self. Ying Zhu and colleagues (Zhu et al. 2007) compared the activity of the mPFC in Chinese and Western ${ }^{8}$ college students. They reported that both sets of participants had strong mPFC activity when making judgments about themselves, in line with previous research. However, they also discovered that when Chinese participants were engaged in making judgments about their mothers, their mPFC was as active as it was when they were engaged in self-judgments, and that the fMRI imaging was indistinguishable across these conditions. This was not the case when Western participants were making judgments about their mothers (Ibid p. 1312). The finding with Chinese participants was replicated by Wang and colleagues (Wang et al. 2011), who examined how mPFC activity changed in Chinese college students when thinking about the self, mother, father or a public figure. Like Zhu and colleagues, they found images of mPFC activity when participants thought about themselves, or their mothers, to be indiscernible. However, there was significantly less mPFC activity when making judgments about their fathers, or public figures.

Zhu and Wang take their findings to indicate that inter-dependent and independent self-construals result in different neural activity in the mPFC. The mother-child bond is extremely close in China (Chao 1994) and, as argued in Sect. 3.2, a mother's expectations inherently shape her child's own self-identity, exemplifying one of the closest inter-dependent relations a person will have through their lives. Zhu writes,

"The relatively heavy emphasis on interpersonal connectedness in Chinese culture has led to the development of neural unification of the self and intimate

\footnotetext{
8 The Western subjects were Caucasians with their native language being English (6 English, 4 American, 2 Australian and 1 Canadian) and had studied in China for less than one year when they participated in this study.
} 
persons such as mother, whereas the relative dominance of an independent self in Western cultures results in neural separation between self and others (even close others such as mother)"(Chao 1994).

Zhu and Wang's laboratories studied cross-cultural differences in mPFC activity when participants thought about themselves or close others. Yina Ma and colleagues compared mPFC activity across Danish and Chinese participants while they made judgments about themselves along three dimensions: physical attributes, personality traits and social roles. They hypothesised that the independent self-construal prevalent in Danish 'Individualist'-oriented culture would result in greater mPFC activity when they engaged in self-judgments, in contrast to Chinese participants. Their results supported their hypothesis, showing significant mPFC activity across both groups, but greater activity for Danish in contrast to Chinese participants. ${ }^{9}$ The researchers' second hypothesis was that an inter-dependent self-construal requires thinking about how others perceive you. Such reasoning involves mindreading, namely, working out how others think of you and how that affects your self-identity. As the TPJ is the region associated with mindreading, they hypothesised that Chinese participants should show increased TPJ activity when engaged in self-judgments, in contrast to Danish participants. This hypothesis was supported by the data, with the researchers reporting "Chinese showed significantly stronger TPJ actitivity than Danes during self-reflection on social attributes [...] but not during self reflection on physical or mental attributes" (Ma et al. 2014, 76). In addition, they reported "greater functional connectivity between the mPFC and the bilateral TPJ associated with self-reflection on social attributes was significantly stronger in Chinese than Danes" (Ibid, p. 77), suggesting that an inter-dependent self-construal causes these two neural regions to become more closely associated in self-reflection than they are in participants with an independent self-construal.

Together these findings provide tentative early support that culture can affect the neural regions associated with one's self-perception, and perception of others. As neuroscience papers, they are each open to the problems of appropriate inference, fine-grained analyses of voxel patterns, and the debate about consistency versus probabilistic use of the imaging data (Glymour and Hanson 2016; Klein 2010). In particular, Zhu's interpretation of their data quoted above may be too strong: the findings are consistent with the hypothesis that self- and mother-judgments would heavily use the same brain regions, due to the way Collective self-construal shapes an inter-dependent sense of self; but it is not yet clear that this is the case. However, the data put forward the possibility that culture can shape social cognition, and philosophers working on accounts of mindreading and social cognition should at least be mindful that cultural differences could shape cognitive architecture, and not just 'folk' level explanations.

Section three argued that, in isolation, the 'Collectivist' and 'Individualist' labels are too broad to generate testable hypotheses. In the work since discussed, I have shown that a more nuanced understanding of which others have the most influence on your self-construal (e.g. your mother), based on cultural values, can give rise to

\footnotetext{
9 This study, and the previous ones, have been significantly simplified to present the headline findings. In each case, the 'results' reported here are based on multiple, convergent analyses of the imaging (i.e. Region-of-interest analyses and whole brain analyses).
} 
hypotheses that can be explored through neural imaging. ${ }^{10}$ If we have successfully identified the regions of interest for attributing psychological states to ourselves and others (TPJ and mPFC), then we can examine how activity in these areas differs across participants whose cultures place more or less emphasis on the importance of other's thoughts about them. Similarly, we can examine this neural activity across participants whose cultural values make them more or less likely to think about a target's psychological states in a particular situation. For example, Rebecca Saxe and colleagues have reported increased activity in (North American) participants when they read stories about people's mental states, in contrast to when they read stories describing people in physical detail, or about non-human objects (Saxe and Kanwisher 2003). Would we expect a difference in TPJ activity across Hindu and North American participants reading the motorcycle anecdote in 3.2? Such hypotheses go beyond broad-brush construals of Collectivism and Individualism.

\subsection{Scientists are folk too}

In a survey of journals from 2003-2007 covering six sub-disciplines of psychology, $99 \%$ of the papers were first authored by academics from Western universities, while $96 \%$ of the participants in the reported studies came from WEIRD ${ }^{11}$ countries (Henrich et al. 2010, 3). As the authors of this work acknowledge, "This means that $96 \%$ of psychological samples come from $12 \%$ of the world's population" (Ibid.). Henrich and colleagues' paper makes a convincing case for the narrowness of the participant pool used by the psychological sciences. But it also highlights another confound, namely, that the researchers doing the work are from WEIRD countries, with $73 \%$ of first authors from the US. This could mean that the psychological constructs that these researchers are looking for and testing with their experiments are themselves shaped by the individualistic tendencies that shape those researchers' own folk psychologies. This problem has been recognised more broadly for neuroscience (Dewhurst 2017, 2018; Poldrack 2010) and there is plenty of research to be done to better understand the effect of folk-psychological trends on scientists' work. To take one toy example: if one believes in the strong domain specificity of neural regions, then the domains one may begin to look for may well be influenced by one's own folk-concepts of cognition. If attributing psychological states to others plays a central role in one's culture, one may be motivated to look for mindreading capacities distinct from other cognitive processes; if, however, such attributions are less important in your culture, you may instead look for neural correlates of 'social role' recognition, or recognition of one's place within a broader network. Folk concepts can be an helpful starting point for scientific inquiry, and, as acknowledged in the argument in 5.1, abilities like 'attributing psychological states to others' are no doubt universal both in folk-psychology and cognitive architecture. But the fact that a cognitive ability exists universally does not

\footnotetext{
10 As a contrastive illustration, Bradford et al. (2018) claimed to find no difference in Chinese and Western responses to self- and other- false belief tasks. However, her prediction was simply that the Collectivism of Chinese culture would lead to less differentiation of the self, without looking at which relations would have the strongest effect; and her stimuli were sentences regarding a fictional agent who participants never saw or knew anything at all about.

11 Western, Educated, Industrialised, Rich, Democratic
} 
mean it is used to the same extent across cultures, nor does it necessarily imply the same neural or cognitive underpinnings due to the different functions it may have across cultures. Acknowledging these complexities is critical for developing a clear understanding of the cognitive architecture of mindreading.

\subsection{Impact on mindreading theories}

This section and the previous one have argued that there are real differences in mindreading across cultural groups. ${ }^{12}$ That individuals can have different mindreading goals in the same situation has been discussed at length elsewhere (Spaulding 2018a; Westra 2017). But this paper has suggested that the picture is even more complex: mindreading methods that have one goal for one cultural group can have quite a different one for another group. Furthermore, cultural constructs like the inter- or independence of the self may result in neural correlates associated with mindreading or self-reference to differ across cultural groups. While the primary aim of this paper is to make the case that this is an important explanandum that has largely been ignored by theories of mindreading, it has tried to remain neutral on which theories of mindreading might best address it. Here I offer some preliminary comments on how existing theories may be affected.

One current debate in the mindreading literature pertains to whether we 'automatically' attribute psychological states to others and, if we do, what sorts of psychological states these are (Apperly 2010; Carruthers 2016; Christensen and Michael 2016). 'Automatic' in this context means that we attribute psychological states to others regardless of whether doing so is relevant to our explicit goals. For example, in a popular method for measuring automatic mindreading, participants are shown a series of scenes of a room with dots on the wall, and in some scenes an avatar is present who can see a different number of dots to the participant (e.g. because a barrier blocks the avatar's visual access to some of the dots). Participants are asked to judge how many dots they can see, a task that does not require any acknowledgment of the avatar's perspective. The original finding (Samson et al. 2010) is that participants are slower to judge how many dots there are when the avatar sees a different number of dots, a result interpreted by the experimenters as showing that participants are automatically calculating the avatar's perspective even though doing so in not only unnecessary for the task in hand, but detrimental as it slows their responses to the explicit question.

Replication attempts of the dot perspective task have been messy and yielded a conflicting array of interpretations of the data (see O'Grady et al. 2017 for a review). One possible explanation for this confusion may be the assumption that the 'automaticity' of mindreading is the same for all people. If someone is raised to believe that it is vitally important to consider the impact of your actions on another person [e.g. as is the case in Japanese culture (Markus and Kitayama 1991, p.229)] then we might predict automatic mindreading in the dot-perspective task. If one does not have this cultural norm then mindreading may not be automatic, but 'spontaneous', meaning

\footnotetext{
12 See Spaulding (2017) and Curry (2018) for more on the differences in mindreading within relatively similar populations.
} 
that it quickly occurs if the task demands it (and does so non-consciously) (Carruthers 2016).

'Two systems' theories of mindreading maintain that there is an universal quick and efficient mindreading system that allows us to attribute non-propositional psychological states to others, and use data from dot-perspective tasks showing a slower response when an avatar has a different perspective to the participant to support this claim (Apperly and Butterfill 2009; Apperly 2010; Butterfill and Apperly 2013; Low et al. 2016). Further bolstering their universality assumption, the theory also maintains that this automatic mindreading system is shared with non-human primates and possibly other animals. But considerations of individual differences in responding to these tasks (based, in some part, on cultural factors) might mean that the conditions under which the quick and efficient mindreading system is active could differ across populations. This doesn't preclude the quick and efficient system from being shared with other animals, but instead opens the possibility that the use of this system might vary. It does, however, affect a claim to rigid encapsulation of the quick and efficient mindreading system that some two-theorists advocate (Apperly 2010, p.154): if cultural background can effect the conditions under which this mindreading system is active, there must be some way for these cultural norms to affect it, and so the system cannot be completely isolated from the rest of the cognitive system. ${ }^{13}$

Celia Heyes is a vocal critic of 'Two systems' theories of mindreading, maintaining that the data from dot-perspective tasks are best explained by processes that do not involve calculating the avatar's perspective (Heyes and Frith 2014; Santiesteban et al. 2014), but rather by processes that orient our attention to the direction of the avatar's gaze. Her explanation of the data is a strictly non-psychological one, and her broader theory of mindreading maintains that it is a culturally learned ability, a view that sits well with the ideas presented in this paper. But her account does not consider the possibility that the 'learned' ability that is mindreading may affect whether one uses a non-psychological strategy or a psychological one in situations like that of the dotperspective task. In the light of the work discussed in 5.2, it is not clear that such a possiblity should be screened off from the outset; again, this is another possible way in which cultural considerations could affect contemporary accounts of mindreading.

\section{Conclusions}

This paper has advanced two claims. The first is that methods and goals for mindreading vary significantly across cultures. This goes beyond Spaulding's original observation that we have different explanatory goals for out-group and in-group members, which in itself predicts that two people with a different relation to a target will use different methods to mindread them. It broadens the scope of this observation, to show that strategies used in one cultural setting (e.g. North America) to gain a quick but likely inaccurate understanding of an outgroup member, can be used in another (e.g. China) to gain an accurate understanding of a close relative. This is due to different folk per-

\footnotetext{
13 It is the encapsulation of the quick and efficient mindreading system that is meant to explain how it can operate quickly and efficiently (Apperly 2010), but this requirement is contested (see footnote 4).
} 
ceptions of what accuracy entails: thinking about another's psychological motivations, versus reasoning about what is expected of that person given their social roles. The second claim is that acknowledging this difference in folk-explanations affects our understanding of the processes of mindreading. For, while mindreading is no doubt an universal cognitive ability, the extent to which it is used will be shaped by cultural defaults for explanations of behaviour. This nuance means that while Fodor was likely correct that there is no group that doesn't offer explanations of behaviour by reference to propositional attitudes, the weight given to this process, even at non-folk levels of explanation, will vary according to cultural norms.

The aim of the paper has been to advocate a particular explanandum for social cognition: that cultural differences in folk-explanations and their consequent effect on mindreading processes needs to be accommodated in current and future theories. But it has not pinned its colours to any particular account of how mindreading and folk-psychology relate. Instead, it offers a constraint: theories must allow that folk-psychological norms will affect the mechanisms of mindreading by making psychological state attribution more or less salient. For too long cross-cultural considerations have been an afterthought in theories of mindreading; the current pluralistic movement to expand our understanding of mindreading and folk psychology beyond propositional attitudes, explanation, and prediction, provides an excellent opportunity to bring culture back into the explanatory fold.

Acknowledgements I am grateful to Lucy Pickering and two anonymous reviewers for their comments on this paper. I would also like to thank Alasdair Richmond for helpful discussions about the nature of explanation.

Open Access This article is distributed under the terms of the Creative Commons Attribution 4.0 International License (http://creativecommons.org/licenses/by/4.0/), which permits unrestricted use, distribution, and reproduction in any medium, provided you give appropriate credit to the original author(s) and the source, provide a link to the Creative Commons license, and indicate if changes were made.

\section{References}

Ames, D . R. (2004). Inside the mind reader's tool kit: Projection and stereotyping in mental state inference. Journal of Personality and Social Psychology, 87(3), 340.

Ames, D. R., \& Mason, M. F. (2012). Mind perception. In S. Fiske \& C. N. McCrae (Eds.), The SAGE handbook of social cognition (pp. 115-137). CA: Sage Thousand Oaks.

Andrews, K. (2008). It's in your nature: A pluralistic folk psychology. Synthese, 165(1), 13-29.

Andrews, K. (2012). Do apes read minds?: Toward a new folk psychology. Cambridge: MIT Press.

Apperly, I. (2010). Mindreaders: The cognitive basis of "theory of mind". Abingdon: Psychology Press.

Apperly, I. A., \& Butterfill, S. A. (2009). Do humans have two systems to track beliefs and belief-like states? Psychological Review, 116(4), 953.

Barrett, H. C., Bolyanatz, A., Crittenden, A. N., Fessler, D. M., Fitzpatrick, S., Gurven, M., et al. (2016). Small-scale societies exhibit fundamental variation in the role of intentions in moral judgment. Proceedings of the National Academy of Sciences, 113(17), 4688-4693.

Barrett, H. C., Broesch, T., Scott, R. M., He, Z., Baillargeon, R., Wu, D., et al. (2013a). Early false-belief understanding in traditional non-western societies. Proceedings of the Royal Society B: Biological Sciences, 280(1755), 1-6.

Barrett, H. C., Broesch, T., Scott, R. M., He, Z., Baillargeon, R., Wu, D., et al. (2013b). Supplementary material: Early false-belief understanding in traditional non-western societies. Proceedings of the Royal Society B: Biological Sciences, 280(1755), 1471-2954. 
Bradford, E. E., Jentzsch, I., Gomez, J.-C., Chen, Y., Zhang, D., \& Su, Y. (2018). Cross-cultural differences in adult theory of mind abilities: A comparison of native-english speakers and native-chinese speakers on the self/other differentiation task. Quarterly Journal of Experimental Psychology, 71(12), 2665-2676.

Butterfill, S. A., \& Apperly, I. A. (2013). How to construct a minimal theory of mind. Mind \& Language, 28(5), 606-637.

Carruthers, P. (1996). Simulation and self-knowledge: A defence of theory-theory. In P. Carruthers \& P. K. Smith (Eds.), Theories of theories of mind (pp. 22-38). Cambridge: Cambridge University Press.

Carruthers, P. (2006). The architecture of the mind. Oxford: Oxford University Press.

Carruthers, P. (2016). Two systems for mindreading? Review of Philosophy and Psychology, 7(1), 141-162.

Chao, R. K. (1994). Beyond parental control and authoritarian parenting style: Understanding chinese parenting through the cultural notion of training. Child Development, 65(4), 1111-1119.

Christensen, W., \& Michael, J. (2016). From two systems to a multi-systems architecture for mindreading. New Ideas in Psychology, 40, 48-64.

Chua, A. (2011). Battle hymn of the tiger mother. London: Bloomsbury.

Craik, F. I., Moroz, T. M., Moscovitch, M., Stuss, D. T., Winocur, G., Tulving, E., et al. (1999). In search of the self: A positron emission tomography study. Psychological Science, 10(1), 26-34.

Curry, D. S. (2018). Interpretivism and norms. Philosophical Studies pp. 1-26.

Davidoff, J. (2001). Language and perceptual categorisation. Trends in Cognitive Sciences, 5(9), 382-387.

De Jaegher, H., Di Paolo, E., \& Gallagher, S. (2010). Can social interaction constitute social cognition? Trends in Cognitive Sciences, 14(10), 441-447.

Dennis, T. A., Talih, M., Cole, P. M., Zahn-Waxler, C., \& Mizuta, I. (2007). The socialization of autonomy and relatedness: Sequential verbal exchanges in japanese and us mother-preschooler dyads. Journal of Cross-Cultural Psychology, 38(6), 729-749.

Dewhurst, J. (2017). From folk psychology to cognitive ontology (Doctoral dissertation) (Order No. 10957739). Available from ProQuest Dissertations \& Theses Global. (2083742764).

Dewhurst, J. (2018). Context-sensitive ontologies for a non-reductionist cognitive neuroscience. Australasian Philosophical Review, 2, 224-228.

Fiske, S. T. \& Neuberg, S. L. (1990). A continuum of impression formation, from category-based to individuating processes: Influences of information and motivation on attention and interpretation. In Advances in experimental social psychology (vol. 23, pp. 1-74). Elsevier.

Fodor, J. (1989). Psychosemantics. Cambridge: MIT Press.

Fu, A. S., \& Markus, H. R. (2014). My mother and me: Why tiger mothers motivate asian americans but not european americans. Personality and Social Psychology Bulletin, 40(6), 739-749.

Gallagher, S. (2008). Inference or interaction: Social cognition without precursors. Philosophical Explorations, 11(3), 163-174.

Gilbert, D . T., Krull, D . S., \& Pelham, B . W. (1988). Of thoughts unspoken: Social inference and the self-regulation of behavior. Journal of Personality and Social Psychology, 55(5), 685.

Glymour, C., \& Hanson, C. (2016). Reverse inference in neuropsychology. British Journal for the Philosophy of Science, 67(4), 1139-1153.

Goldman, A. I. (1992). In defense of the simulation theory. Mind \& Language, 7(1-2), 104-119.

Goldman, A. I., et al. (2006). Simulating minds: The philosophy, psychology, and neuroscience of mindreading. Oxford: Oxford University Press.

Gopnik, A., \& Wellman, H . M. (2012). Reconstructing constructivism: Causal models, bayesian learning mechanisms, and the theory theory. Psychological Bulletin, 138(6), 1085.

Gordon, R. M. (1992). The simulation theory: Objections and misconceptions. Mind \& Language, 7(1-2), $11-34$.

Gutchess, A. H., Welsh, R. C., Boduroglu, A., \& Park, D. C. (2006). Cultural differences in neural function associated with object processing. Cognitive, Affective, \& Behavioral Neuroscience, 6(2), 102-109.

Han, S., \& Humphreys, G. (2016). Self-construal: A cultural framework for brain function. Current Opinion in Psychology, 8, 10-14.

Heatherton, T. F. (2011). Neuroscience of self and self-regulation. Annual Review of Psychology, 62, 363390.

Heine, S. J., \& Lehman, D. R. (1997). Culture, dissonance, and self-affirmation. Personality and Social Psychology Bulletin, 23(4), 389-400.

Henrich, J., Heine, S. J., \& Norenzayan, A. (2010). The weirdest people in the world? Behavioral and Brain Sciences, 33(2-3), 61-83.

Heyes, C. M., \& Frith, C. D. (2014). The cultural evolution of mind reading. Science, 344(6190), 1243091. 
Hutto, D. D. (2008). Folk psychological narratives. Cambridge: The Sociocultural Basis of Understanding Reasons.

Hutto, D. D. (2017). Basic social cognition without mindreading: Minding minds without attributing contents. Synthese, 194(3), 827-846.

Iyengar, S. S., \& Lepper, M. R. (1999). Rethinking the value of choice: A cultural perspective on intrinsic motivation. Journal of Personality and Social Psychology, 76, 349-366.

Kelley, H . H. (1973). The processes of causal attribution. American Psychologist, 28(2), 107.

Kelley, W. M., Macrae, C. N., Wyland, C. L., Caglar, S., Inati, S., \& Heatherton, T. F. (2002). Finding the self? An event-related fmri study. Journal of Cognitive Neuroscience, 14(5), 785-794.

Kim, H . S., \& Sherman, D . K. (2007). "express yourself": Culture and the effect of self-expression on choice. Journal of Personality and Social Psychology, 92(1), 1.

Kitayama, S., \& Park, J. (2010). Cultural neuroscience of the self: Understanding the social grounding of the brain. Social Cognitive and Affective Neuroscience, 5(2-3), 111-129.

Kiverstein, J. (2011). Social understanding without mentalizing. Philosophical Topics, 39(1), 41-65.

Klein, C. (2010). Philosophical issues in neuroimaging. Philosophy Compass, 5(2), 186-198.

Koster-Hale, J., \& Saxe, R. (2013). Functional neuroimaging of theory of mind. In Understanding other minds: Perspectives from developmental social neuroscience (pp. 132-163).

Krueger, J. (1998). On the perception of social consensus. In Advances in experimental social psychology (vol. 30, pp. 163-240). Elsevier.

Lavelle, J. S. (2018). The social mind: A philosophical introduction. Abingdon: Routledge.

Lieberman, M . D., Jarcho, J . M., \& Satpute, A . B. (2004). Evidence-based and intuition-based selfknowledge: An fmri study'. Journal of Personality and Social Psychology, 87(4), 421.

Lillard, A. (1998). 'Ethnopsychologies: Cultural variations in theories of mind'. Psychological Bulletin, $123(1), 3$.

Low, J., Apperly, I. A., Butterfill, S. A., \& Rakoczy, H. (2016). Cognitive architecture of belief reasoning in children and adults: A primer on the two-systems account. Child Development Perspectives, 10(3), 184-189.

Ma, Y., Bang, D., Wang, C., Allen, M., Frith, C., Roepstorff, A., et al. (2014). Sociocultural patterning of neural activity during self-reflection. Social Cognitive and Affective Neuroscience, 9(1), 73-80.

Markus, H . R., \& Kitayama, S. (1991). Culture and the self: Implications for cognition, emotion, and motivation. Psychological Review, 98(2), 224.

McGeer, V. (2007). The regulative dimension of folk psychology. In Folk psychology re-assessed (pp. 137-156). Springer.

Miller, J. (1984). Culture and the development of everyday social explanation. Journal of Personality and Social Psychology, 46(5), 961-978.

Miller, J. (2001). The cultural grounding of social psychological theory. In A. Tesser \& N. Schwarz (Eds.), Blackwell handbook of social psychology: Intraindividual processes (pp. 22-43). Blackwell.

Miller, J. (2002). Bringing culture to basic psychological theory-beyond individualism and collectivism: Comment on oyserman et al. (2002). Psychological Bulletin, 128(1), 97-109.

Miller, P . J., Wang, S-h, Sandel, T., \& Cho, G . E. (2002). Self-esteem as folk theory: A comparison of european american and taiwanese mothers' beliefs. Parenting: Science and Practice, 2(3), 209-239.

Morris, M . W., \& Peng, K. (1994). Culture and cause: American and chinese attributions for social and physical events. Journal of Personality and Social psychology, 67(6), 949.

Morton, A. (2003). The importance of being understood: Folk psychology as ethics. Routledge: International library of philosophy.

Nichols, S., \& Stich, S. (2003). Mindreading: An integrated account of pretence, self-awareness, and understanding other minds. Oxford: Oxford University Press.

Nisbett, R. (2004). The geography of thought: How Asians and Westerners think differently... and why. New York: Simon and Schuster.

Nisbett, R. E., Peng, K., Choi, I., \& Norenzayan, A. (2001). Culture and systems of thought: Holistic versus analytic cognition. Psychological Review, 108(2), 291.

O’Grady, C., Scott-Phillips, T., Lavelle, S. \& Smith, K. (2017). The dot perspective task revisited: Evidence for directional effects. In G. Gunzelmann, A. Howes, T. Tenbrink \& E. Davelaar, (Eds.), Proceedings of the 39th annual meeting of the cognitive science society Cognitive Science Society. 
Oyserman, D., Coon, H. M., \& Kemmelmeier, M. (2002). Rethinking individualism and collectivism: Evaluation of theoretical assumptions and meta-analyses. Psychological Bulletin, 128(1), 3.

Poldrack, R. A. (2010). Mapping mental function to brain structure: How can cognitive neuroimaging succeed? Perspectives on Psychological Science, 5(6), 753-761.

Ratcliffe, M. (2006). Rethinking commonsense psychology: A critique of folk psychology, theory of mind and simulation. Berlin: Springer.

Ratcliffe, M. (2007). From folk psychology to commonsense. In D. Hutto \& M. Ratcliffe (Eds.), Folk psychology re-assessed (pp. 223-243). Berlin: Springer.

Robbins, J., \& Rumsey, A. (2008). Introduction: Cultural and linguistic anthropology and the opacity of other minds. Anthropological Quarterly, 81(2), 407-420.

Samson, D., Apperly, I. A., Braithwaite, J. J., Andrews, B. J., \& Bodley Scott, S. E. (2010). Seeing it their way: Evidence for rapid and involuntary computation of what other people see. Journal of Experimental Psychology: Human Perception and Performance, 36(5), 1255.

Santiesteban, I., Catmur, C., Hopkins, S. C., Bird, G., \& Heyes, C. (2014). Avatars and arrows: Implicit mentalizing or domain-general processing? Journal of Experimental Psychology: Human Perception and Performance, 40(3), 929.

Saxe, R. (2013). The new puzzle of theory of mind development. In Navigating the social world: What infants, children, and other species can teach us (pp. 107-112). New York: Oxford University Press.

Saxe, R., \& Kanwisher, N. (2003). People thinking about thinking people: The role of the temporo-parietal junction in "theory of mind". Neuroimage, 19(4), 1835-1842.

Schneider, D., Slaughter, V. P., \& Dux, P. E. (2017). Current evidence for automatic theory of mind processing in adults. Cognition, 162, 27-31.

Schwartz, S. H. (1990). Individualism-collectivism: Critique and proposed refinements. Journal of CrossCultural Psychology, 21(2), 139-157.

Shahaeian, A., Nielsen, M., Peterson, C. C., \& Slaughter, V. (2014). Iranian mothers' disciplinary strategies and theory of mind in children: A focus on belief understanding. Journal of Cross-Cultural Psychology, 45(7), 1110-1123.

Spaulding, S. (2017). How we think and act together. Philosophical Psychology, 30(3), 302-318.

Spaulding, S. (2018a). Do you see what i see? How social differences influence mindreading. Synthese, 195(9), 4009-4030.

Spaulding, S. (2018b). How we understand others: Philosophy and social cognition. Abingdon: Routledge.

Spaulding, S. (2018c). Mindreading beyond belief: A more comprehensive conception of how we understand others. Philosophy Compass, 13(11), e12526.

Stich, S., \& Nichols, S. (1992). Folk psychology: Simulation or tacit theory? Mind \& Language, 7(1-2), 35-71.

Tetlock, P. E. (1992). The impact of accountability on judgment and choice: Toward a social contingency model. Advances in Experimental Social Psychology, 25, 331-376.

Triandis, H. (1995). Individualism and Collectivism, Westview.

Vorauer, J. D., Hunter, A., Main, K. J., \& Roy, S. A. (2000). Meta-stereotype activation: Evidence from indirect measures for specific evaluative concerns experienced by members of dominant groups in intergroup interaction. Journal of Personality and Social Psychology, 78(4), 690.

Vygotsky, L. S. (1980). Mind in society: The development of higher psychological processes. Cambridge: Harvard University Press.

Wang, G., Mao, L., Ma, Y., Yang, X., Cao, J., Liu, X., et al. (2011). Neural representations of close others in collectivistic brains. Social Cognitive and Affective Neuroscience, 7(2), 222-229.

Wellman, H. M. (2014). Making minds: How theory of mind develops. Oxford: Oxford University Press.

Westra, E. (2017). Stereotypes, theory of mind, and the action-prediction hierarchy. Synthese, 196, 1-26.

Westra, E. (2018). Character and theory of mind: An integrative approach. Philosophical Studies, 175(5), 1217-1241.

Zawidzki, T. W. (2008). The function of folk psychology: Mind reading or mind shaping? Philosophical Explorations, 11(3), 193-210.

Zawidzki, T. W. (2013). Mindshaping: A new framework for understanding human social cognition. Cambridge: MIT Press. 
Zhang, L., Zhou, T., Zhang, J., Liu, Z., Fan, J., \& Zhu, Y. (2006). In search of the chinese self: An fmri study. Science in China Series C, 49(1), 89-96.

Zhu, Y., Zhang, L., Fan, J., \& Han, S. (2007). Neural basis of cultural influence on self-representation. Neuroimage, 34(3), 1310-1316.

Publisher's Note Springer Nature remains neutral with regard to jurisdictional claims in published maps and institutional affiliations. 